\title{
High-Definition tDCS of Noun and Verb Retrieval in Naming and Lexical Decision
}

\author{
Svetlana Malyutina ${ }^{1,2^{*}}$ and Dirk-Bart den Ouden ${ }^{1,2}$ \\ ${ }^{1}$ University of South Carolina, Department of Communication Sciences and Disorders, Columbia, South Carolina, USA \\ ${ }^{2}$ National Research University Higher School of Economics (HSE), Moscow, Russia
}

\begin{abstract}
High-definition transcranial direct current stimulation (HD-tDCS) is a novel brain stimulation method that has high potential for use in language therapy for speakers with aphasia, due to its safety and focality. This study aimed to obtain foundational data on using HD-tDCS to modulate language processing in healthy speakers. Participants received stimulation either of Broca's area or of the left angular gyrus (20 min of anodal, cathodal, and sham stimulation on separate days), followed by naming and lexical decision tasks with single-word verb and noun stimuli. We found that cathodal stimulation over both Broca's area and the left angular gyrus increased naming speed for both verbs and nouns, challenging the traditional view of cathodal stimulation as suppressive or leading to decreased performance. The effect did not extend to the lexical decision task. Additionally, effects of specific stimulation types depended on the order of their administration, suggesting possible physiological carry-over and/or task novelty effects. These results are relevant to the application of HD-tDCS to enhance and direct neural plasticity in patients with neurogenic language disorders.
\end{abstract}

Keywords: HD-tDCS; brain stimulation; language; word retrieval; Broca's area; angular gyrus

Citation: Malyutina, S., \& den Ouden, D-B. (2015). High-Definition tDCS of Noun and Verb Retrieval in Naming and Lexical Decision. NeuroRegulation, 2(3), 111-125. http://dx.doi.org/10.15540/nr.2.3.111

*Address correspondence to: Svetlana Malyutina, Staraya Basmannaya Street 21/4, Room 510,105066 Moscow, Russia. Email: smalyutina@hse.ru

Copyright: (๑ 2015. Malyutina and den Ouden. This is an Open Access article distributed under the terms of the Creative Commons Attribution License (CC-BY).

Edited by:

Genomary Krigbaum, PsyD, Marian University, College of Osteopathic Medicine, Indiana, USA

Reviewed by:

Scott Decker, PhD, University of South Carolina, Department of Psychology, South Carolina, USA

Marvin W. Sams, ND, The Sams Center, Texas, USA

\section{Introduction}

It has been suggested that effects of behavioral speech-language therapy for neurogenic language disorders such as aphasia may be enhanced through brain stimulation (Holland \& Crinion, 2012). Preliminary data show that several types of brain stimulation are capable of modulating language processing. Transcranial magnetic stimulation (TMS), a method that applies magnetic fields through a metal coil to induce electric current in focal brain areas and thus to cause neurons to fire action potentials, has been shown to modulate speech production and perception, as well as lexical, syntactic, and semantic processing, both in neurologically healthy subjects (Devlin \& Watkins, 2007) and in persons with aphasia (PWA; Naeser et al., 2012). Similarly, transcranial direct current stimulation (tDCS), a method that delivers constant low current through electrodes on the scalp and, unlike TMS, is believed to modulate cortical excitability rather than directly cause neurons to fire (Stagg, 2014), has been shown to modulate verbal fluency, picture naming, grammar learning, and other language functions in healthy subjects (Cattaneo, Pisoni, \& Papagno, 2011; de Vries et al., 2010; Fertonani, Rosini, Cotelli, Rossini, \& Miniussi, 2010; Holland et al., 2011; lyer et al., 2005; Sparing, Dafotakis, Meister, Thirugnanasambandam, \& Fink, 2008; Wirth et al., 2011; for a review, see Price, McAdams, Grossman, \& Hamilton, 2015) and PWA (Baker, Rorden, \& Fridriksson, 2010; Fiori et al., 2011; Flöel et al., 2011; Fridriksson, Richardon, Baker, \& Rorden, 2011; Vines, Norton, \& Schlaug, 2011; You, Kim, Chun, Jung, \& Park, 2011; for a review, see Monti et al., 2013).

Recently, a high-definition innovation to tDCS (HDtDCS) has also begun to be applied towards the modulation of language processing (Price, Bonner, 
Hamilton, Peelle, \& Grossman, 2015). Like conventional tDCS, HD-tDCS is based on applying electric current in order to modulate neuronal excitability by acting on the resting membrane potential, affecting sodium and calcium channels, as well as NMDA receptors, and by possibly modulating synaptic activity (Stagg \& Nitsche, 2011). However, an important advantage of HD-tDCS over conventional "sponge" tDCS is its increased focality. HD-tDCS is capable of inducing more intensive electric fields at smaller target locations while leaving others relatively unaffected (Datta et al., 2009), which may potentially be more effective than stimulating broader brain areas. Moreover, there is evidence of high safety and tolerability of HD-tDCS (Borckardt et al., 2012). These characteristics suggest a high potential for routine clinical use and warrant more research on how language processing can be modulated with HD-tDCS, both in the healthy population and ultimately in PWA and people with other language disorders. Similarly to traditional tDCS, HD-tDCS can be anodal (injecting positive charge into the target area and supposedly lowering the neural activation threshold through depolarization) or cathodal (injecting negative charge into the target area and supposedly increasing the neural activation threshold through hyperpolarization), although the dichotomy of anodal versus cathodal stimulation may be an oversimplification, especially for HD-tDCS (Garnett, Malyutina, Datta, \& den Ouden, 2015).

The present study applied HD-tDCS in neurologically healthy participants and targeted a specific aspect of language processing: lexical retrieval, tested with an overt naming task and a lexical (word/non-word) decision task. Lexical retrieval is the crucial prerequisite to performing both tasks, although they also involve other processes that are not shared (e.g., naming but not lexical decision requires articulation, etc.). We tested two grammatical classes of words: verbs and nouns. In one group of participants, we aimed to nonspecifically modulate lexical retrieval of both verbs and nouns, by targeting Broca's area, traditionally associated with a very wide range of speech and language functions (Hagoort, 2005; Thompson-Schill, 2005). In the other group of participants, we aimed to specifically modulate verb processing by targeting posterior temporal/inferior parietal cortex.

Verbs have received special attention in many language treatments for aphasia (Bazzini et al., 2012; Thompson, Riley, den Ouden, MeltzerAsscher, \& Lukic, 2013) because they determine what other words appear in a sentence, in what semantic roles, and in what order and grammatical form (such information is referred to as verb argument structure). For example, it is the argument structure of the verb to give that determines that a sentence containing this verb should include three arguments (participants): Anna gave a book to John. Thus, improvement of verb processing may contribute to general improvement of sentence production and comprehension, and it is of our interest to investigate whether brain stimulation can be used to specifically enhance verb processing, which is more complex than noun processing at a variety of levels (for a review, see Vigliocco, Vinson, Druks, Barber, \& Cappa, 2011). Enhancement is particularly relevant for verbs with more complex argument structure, such as a greater number of arguments, since those have been shown to present the greatest challenge both for healthy individuals (e.g., in grammatical class judgment in RodríguezFerreiro, Andreu, \& Sanz-Torrent, 2014, and lexical decision, Rodríguez-Ferreiro et al., 2014, and Shapiro, Brookins, Gordon, \& Nagel, 1991; see, however, Thompson et al., 2007) and for PWA (e.g., in naming, Kim \& Thompson, 2000; and sentence production, Kiss, 2000, and Thompson, Lange, Schneider, \& Shapiro, 1997). Aiming to specifically modulate verb processing, we targeted the left angular gyrus, since previous neuroimaging research suggests that this area is involved in the processing of verb argument structure. For example, den Ouden, Fix, Parrish, and Thompson (2009) showed activation of the left angular gyrus for naming two-argument verbs (e.g., to kiss, to stir) compared to one-argument verbs (e.g., to jump, to cough), and Thompson, Bonakdarpour, and Fix (2010) showed activation of the left angular gyrus in a lexical decision task when comparing threeargument verbs (e.g., to give, to invite) to oneargument verbs.

Previous studies have already made first attempts to specifically modulate verb processing with brain stimulation. Cappa, Sandrini, Rossini, Sosta, and Miniussi (2012) applied rTMS in healthy participants and found that rTMS over the left (but not right) prefrontal cortex specifically resulted in faster naming of verbs, but not of nouns, presumably due to the role of this region in the processing of action semantics. However, Fertonani et al. (2010) failed to replicate this effect with tDCS in healthy participants: in their study, anodal (but not cathodal) stimulation over the left dorsolateral prefrontal cortex resulted in faster naming of both actions and objects. Marangolo et al. (2013) applied tDCS in PWA and investigated the potential of left frontal 
versus temporal regions to modulate verb processing. They found that anodal tDCS over Broca's area improved verb-naming accuracy compared to anodal tDCS over Wernicke's area and sham; however, the study did not test noun naming and thus cannot exclude that the improvement was not specific to verbs. The present study aimed to add to this line of research by stimulating the left angular gyrus, a region that has received a lot of attention in neuroimaging research of verb processing in relation to the complexity of verb argument structure representations (see above) but has not yet been addressed by brain stimulation research, and by testing performance on both verbs and nouns in order to investigate the specificity of effects, which was not possible in Marangolo et al. (2013).

To summarize, we hypothesized that stimulation of the left angular gyrus would specifically affect verb processing, in particular for more linguistically complex verbs (verbs with a greater number of arguments), whereas stimulation of Broca's area would nonspecifically affect lexical retrieval of both verbs and nouns. We hypothesized that effects would occur at the level of retrieval of lexical items from the mental lexicon and thus be present in both naming and lexical decision tasks, rather than depend on whether the task involves overt speech/articulation processes (naming) or not (lexical decision). In the case of task-specific effects, it is likely that processes other than lexical retrieval are affected by the stimulation; that is, visual processing, object recognition, conceptual/semantic processing, phonological and articulatory planning, and speech motor execution in the naming task, versus reading, response selection, and hand-motor execution in the lexical decision task. Since HD-tDCS is a novel method, an additional purpose of the study was to obtain more data on its safety and tolerability.

\section{Materials and Methods}

\section{Participants}

Twenty-seven healthy volunteers participated in the study (14 females; mean age 22.1, SD 3.2, range 18-31 years; mean number of years of formal education 15.6, SD 2.8, range 12-24). All participants were right-handed and native speakers of American English. All participants had normal or corrected-to-normal vision and hearing and no reported history of neurological, psychiatric, speech, or language disorders. The study was approved by the University of South Carolina Institutional Review
Board. Informed consent was obtained from all individual participants included in the study.

\section{Design}

The stimulation target was left-hemisphere Broca's area in 14 participants (7 females; mean age 22.9, $S D$ 4.0, range 19-31 years; mean number of years of formal education 15.4, SD 2.9, range 12-23; 12 white Caucasians, 1 white Hispanic, 1 Native Hawaiian) and the left angular gyrus in 13 participants (one dropped out of the study due to adverse effects after first session; thus, data of 13 participants were analyzed: 7 females; mean age 21.2, $S D$ 1.8, range 18-29; mean number of years of formal education 15.8, SD 2.9, range 13-24; 12 white Caucasians, 1 Asian). Participants were randomly assigned to one of the two groups. Each participant received anodal, cathodal, and sham stimulation, at similar times of day, with a minimum interval between stimulation sessions of $24 \mathrm{hr}$ (mean number of days $2.8, S D 3.0$, range 1-10). The order of stimulation sessions was maximally counterbalanced across participants. Participants were blinded to their stimulation target and the order of stimulation types. All participants whose data are included into analysis completed all three sessions.

\section{Procedure}

Before stimulation, participants were familiarized with the experimental tasks: they received instructions and examples and completed a short practice session of each task (lexical decision, action naming, and object naming in the order in which they were to be administered after stimulation in the participant; practice stimuli did not overlap with experimental stimuli). Feedback was given during practice. Participants were then administered 20 min of stimulation, during which they performed a non-language distraction task (silently working on a jigsaw puzzle). Participants were asked to verbally rate pain and unpleasantness separately at $0.5,10$, and $19.5 \mathrm{~min}$ after stimulation onset on a scale from 1 (no pain/no unpleasantness) to 10 (very strong pain/very strong unpleasantness). Two experimental language tasks were performed immediately after the stimulation; the order of tasks was maximally counterbalanced across participants.

\section{Stimulation setup}

HD-tDCS was administered through an MxN HDtDCS stimulator (Soterix Medical, New York, NY) with $\mathrm{Ag} / \mathrm{AgCl} \mathrm{HD}$ electrodes (Minhas et al., 2010) placed into an MCN-system (10-10) EEG cap (size 56 or 58, EASYCAP, Herrsching, Germany) and stabilized with HD electrode holders (Soterix Medical, New York, NY) filled with conducting gel 
(SignaGel, Parker Laboratories, Fairfield, NJ). A small amount of benzocaine gel (Lanacane brand) was applied to the skin to reduce any uncomfortable sensations. Lanacane has been routinely used to reduce discomfort during HD-tDCS (e.g., Guleyupoglu et al., 2014). Although it cannot be completely ruled out that any systemic effects caused by the mechanism of action of Lanacane can potentially interfere with effects of HD-tDCS (Scholz, 2002), the dosing in the present study was sufficiently low to consider this possibility as unlikely.
Electrode montages were chosen using HDTargets $^{\mathrm{TM}}$ and HD-Explore ${ }^{\mathrm{TM}}$ software (Soterix Medical, New York, NY) and are presented in Table 1 and Figure 1. For the left Broca's area stimulation, we targeted $\mathrm{MNI}$ coordinates $(-49,16,24)$, which correspond to average peak coordinates in a metaanalysis of sentence processing (Vigneau et al., 2006). For the left angular gyrus stimulation, we targeted MNI coordinates $(-27,-57,51)$, corresponding to the peak activation associated with complex verb processing in (den Ouden et al., 2009).

\section{Table 1}

Electrode configurations.

\begin{tabular}{|c|c|c|c|c|}
\hline $\begin{array}{l}\text { Stimulation } \\
\text { target site }\end{array}$ & Stimulation type & $\begin{array}{l}\text { Electrode configuration } \\
\text { (MCN system) }\end{array}$ & $\begin{array}{l}\text { Resulting intensity } \\
\text { at target } \\
\text { coordinates in the } \\
\text { Broca's area }\end{array}$ & $\begin{array}{l}\text { Resulting intensity } \\
\text { at target } \\
\text { coordinates in the } \\
\text { angular gyrus }\end{array}$ \\
\hline \multirow[t]{3}{*}{ Broca's area } & Anodal & FC5 (+2 mA), AFz (-2 mA) & $0.61 \mathrm{~V} / \mathrm{m}$ & $0.16 \mathrm{~V} / \mathrm{m}$ \\
\hline & Cathodal & $\mathrm{FC} 5(-2 \mathrm{~mA}), \mathrm{AFz}(+2 \mathrm{~mA})$ & $0.61 \mathrm{~V} / \mathrm{m}$ & $0.16 \mathrm{~V} / \mathrm{m}$ \\
\hline & Sham & $\begin{array}{l}\text { AFz (+1 mA), FPz }(-1 m A) \\
\text { FC5 }(+1 m A), F C 3(-1 m A)\end{array}$ & $0.11 \mathrm{~V} / \mathrm{m}$ & $0.01 \mathrm{~V} / \mathrm{m}$ \\
\hline \multirow[t]{3}{*}{ Angular gyrus } & Anodal & CP5 (+2.0 mA), POz (-2.0 mA) & $0.19 \mathrm{~V} / \mathrm{m}$ & $0.52 \mathrm{~V} / \mathrm{m}$ \\
\hline & Cathodal & CP5 (-2.0 mA), POz (+2.0 mA) & $0.19 \mathrm{~V} / \mathrm{m}$ & $0.52 \mathrm{~V} / \mathrm{m}$ \\
\hline & Sham & CP5 (+1 mA), TP7 (-1 mA) & $0.05 \mathrm{~V} / \mathrm{m}$ & $0.06 \mathrm{~V} / \mathrm{m}$ \\
\hline
\end{tabular}

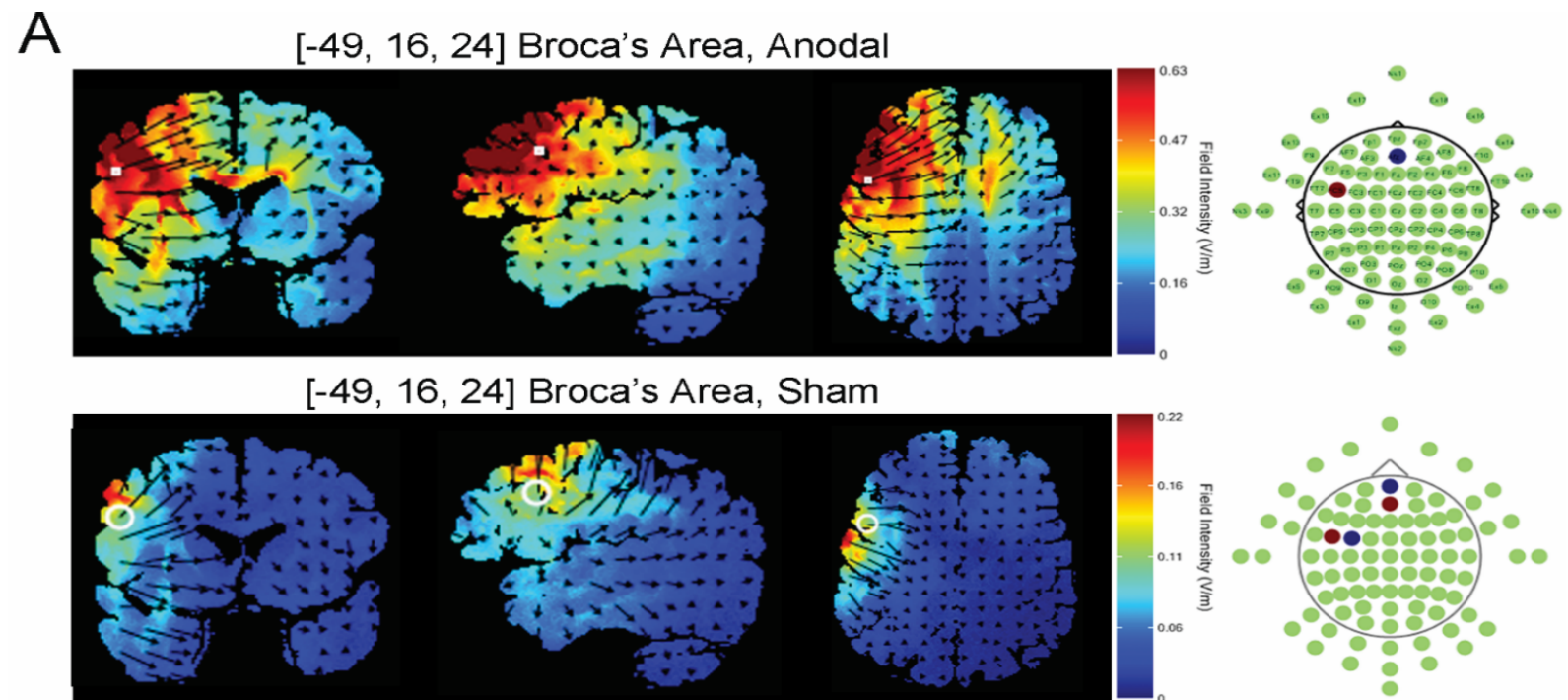

Figure 1. Electrode configurations and resulting field intensities, modeled in $\mathrm{HD}$-Targets ${ }^{\mathrm{TM}}$ and HD-Explore ${ }^{\mathrm{TM}}$ software. Configurations for cathodal stimulation (not shown) were the same as for anodal stimulation but with reversed polarities of electrodes. 

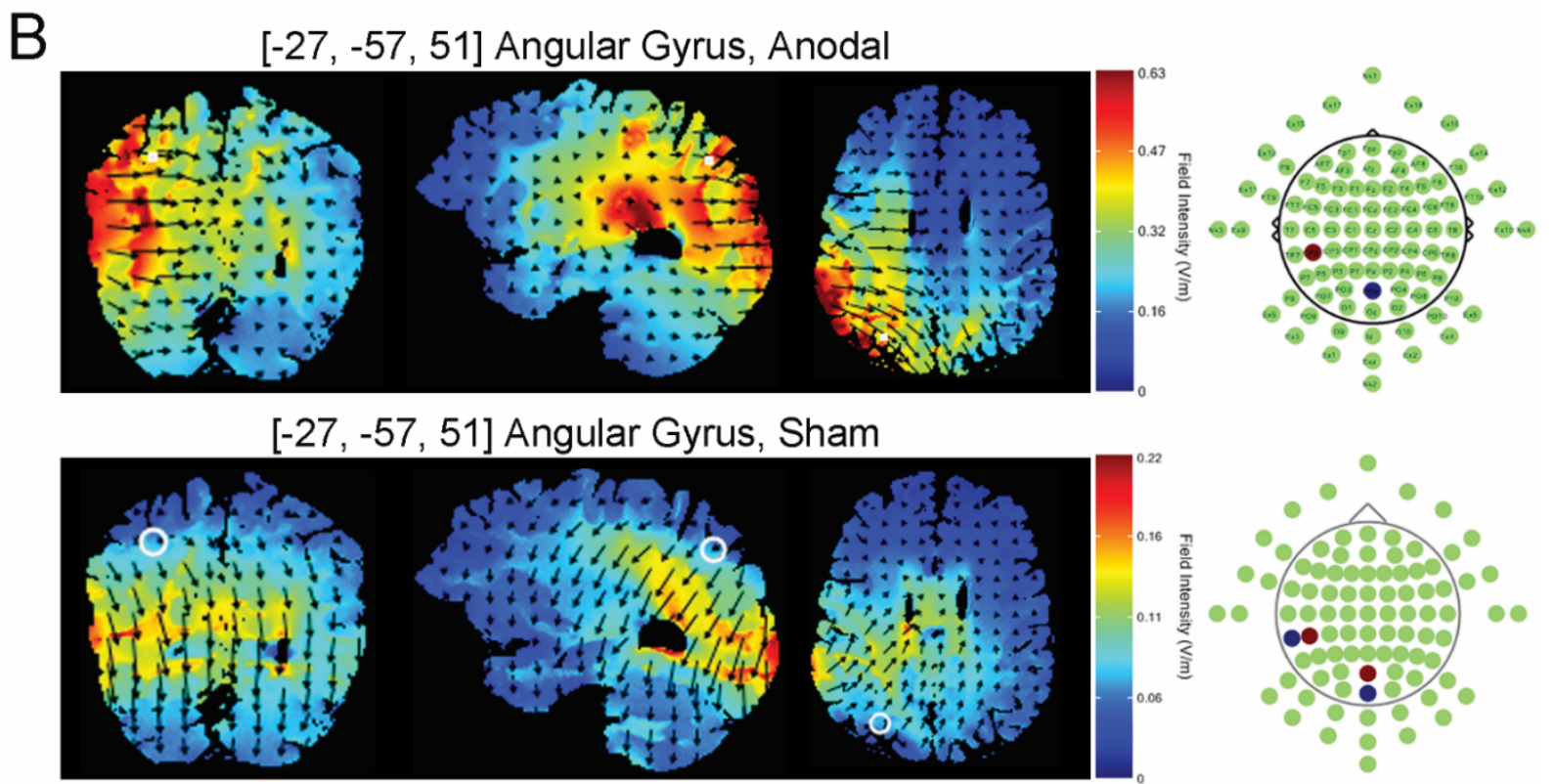

Figure 1. Electrode configurations and resulting field intensities, modeled in HD-Targets ${ }^{\mathrm{IM}}$ and HD-Explore ${ }^{\mathrm{iM}}$ software. Configurations for cathodal stimulation (not shown) were the same as for anodal stimulation but with reversed polarities of electrodes.

For sham, stimulation was also administered for the entire 20 min but in a montage where the current was modeled to bypass the cortex (Davis, Gold, Pascual-Leone, \& Bracewell, 2013; Garnett \& den Ouden, 2015; Kessler, Turkeltaub, Benson, \& Hamilton, 2012; Richardson et al., 2014). Electrodes were placed in proximal pairs so that the current was flowing in and out at adjacent electrodes. To better disguise sham by having equal numbers of electrodes on the participant's scalp across stimulation types, anodal and cathodal setups included two additional electrodes that did not administer any current.

\section{Tasks and Stimuli}

Each participant performed a naming task and a lexical decision task. Order of task administration was counterbalanced across participants. E-Prime software (Psychology Software Tools, Sharpsburg, PA) was used for stimuli presentation and data recording.

Naming task. Participants were shown black-andwhite line drawings on a computer screen and were instructed to name them overtly in single words. Drawings were presented for $3 \mathrm{~s}$ with an interstimulus fixation cross $(1.5 \mathrm{~s})$. Stimuli included 60 pictures of objects to elicit nouns (e.g., shirt, harp) and 60 pictures of actions to elicit verbs, which differed on their argument structure: 30 among them had one argument (i.e., referred to actions not requiring an object, e.g., to laugh, to pray), and 30 had two arguments (i.e., referred to actions requiring an object, e.g., to chase, to grill).

Pictures were taken from a Russian database of action pictures (Akinina et al., 2015) and their English names were normed in a preliminary survey, completed by 61 participants without reported history of neurological, psychiatric, speech, or language disorders (43 females; mean age 33.5, SD 12.8 , range 17-66 years). Only items with name agreement greater than $70 \%$ were included in the experimental materials (mean $91.6 \%, S D 8.0 \%$, range $70-100 \%)$.

Nouns, one-argument verbs, and two-argument verbs were matched on their length in phonemes and syllables, name agreement, as well as lexical frequency and familiarity ratings obtained from the MRC Psycholinguistic Database (Coltheart, 1981). One-argument and two-argument verbs were also matched on the number of objects present in the picture (to ensure that any differences between the two conditions were linguistic/representational, rather than perceptual in nature) and on the percentage of their verb use (to account for any effects of verb-noun homonymy, such as to hammer - a hammer), estimated by manually counting types of use in 100 random contexts from the Corpus of Contemporary American English (http://corpus.byu.edu/coca/). 
Stimuli were split, to be used in three sessions $(20$ nouns, 10 one-argument verbs, and 10 twoargument verbs in each), balanced on the same parameters. Noun and verb stimuli were presented separately, to ensure clarity of whether an action or an object needed to be named. The order of noun/verb naming was counterbalanced and the order of items within verbs/nouns was randomized. In each session, the naming task took approximately three minutes to complete.

Lexical decision task. Participants were presented with strings of letters on a computer screen and instructed to press one button for real English words and another button for non-words. Strings of letters were presented for $1.2 \mathrm{~s}$ with an interstimulus fixation cross $(0.5 \mathrm{~s})$. Stimuli included 90 nouns (e.g., price, word), 90 verbs (verbs differed on their argument structure: 30 had one argument, e.g., swear, wait; 30 had two arguments, e.g., produce, conduct; and 30 had three arguments, that is, referred to an action requiring a direct and an indirect object, e.g., send, provide) and 360 pronounceable non-words (e.g., mipe, assect). Nonwords were constructed by recombining pronounceable segments of real words.

Nouns and the three verb types were matched on lexical frequency and imageability obtained from the MRC Psycholinguistic Database (Coltheart, 1981), orthographic neighborhood (Medler \& Binder, 2005) and length in letters and syllables. Words and nonwords were matched on length in letters and syllables and orthographic neighborhood. The three verb types were matched on the percentage of their verb use (to account for the effects of verb-noun homonymy).

Stimuli were split, to be used in three sessions (30 nouns, 10 verbs of each type, and 120 non-words in each), balanced on the same parameters. The order of stimuli was randomized within each session. In each session, the lexical decision task took approximately five minutes to complete.

\section{Data Analysis}

Statistical analysis was performed in the SPSS 22.0 software (SPSS Inc., Armonk, NY). Pain and unpleasantness ratings were analyzed in two repeated-measures ANOVAs with Stimulation Site as a between-subjects variable and Timepoint and Stimulation Type as within-subject variables.

For the naming task, the analyzed outcomes were the percentage of accurate responses (responses were scored as accurate if given for a picture by at least two respondents in preliminary surveys), number of self-corrections and average reaction time (RT; i.e., time until response onset, based on visual analysis of the speech signal in Praat software [Boersma, 2001]). For the lexical decision task, the outcome measures were the percentage of accurate responses and average RT. Since accuracy and reaction times are typically skewed, they were log-transformed to approach the normal distribution, as is widely conventional for both of these outcome measures (Bartlett, 1947; Baayen \& Milin, 2010; Hoyle, 1973).

For each outcome measure, analysis was performed over average values per condition per participant (i.e., data were aggregated across individual trials). We used the "linear mixed-effects" (MIXED) procedure in SPSS 22.0 with Subject as a random factor, one between-subject variable: Stimulation Site (Broca's area, the left angular gyrus), and three within-subject variables: Linguistic Condition (noun, one-argument verb, two-argument verb, and threeargument verb, where present), Stimulation Type (anodal, cathodal, sham) and Session Number (1, 2, 3 ), with subsequent pairwise comparisons for significant effects. Session number was included into the model in order to statistically account for any practice effects (such as participants getting better at the task across sessions due to experience) and to allow us to include the maximum number of participants whose data were collected, rather than to have to limit the analysis to exactly equal sample sizes assigned to each order of session administration (since the numbers of participants completing stimulation in each order were maximally counterbalanced but not exactly the same).

Since the above analysis consistently revealed interactions between Session Number and Stimulation Type (see section 3.2 below), we concluded that there may exist carry-over effects between sessions. Therefore, we conducted a post hoc and complementary exploratory analysis limited to the data from each participant's first session only, which cannot be subject to any carry-over effects. Due to the smaller number of observations in this exploratory analysis, we performed separate Kruskal-Wallis tests for each linguistic condition with Stimulation Type as a between-subjects factor, followed-up by Bonferroni-corrected Mann-Whitney $\mathrm{U}$ tests for pairwise comparisons. 


\section{Results}

Safety, Tolerability and Sham Masking Mean pain and unpleasantness ratings are presented in Table 2. Repeated-measures ANOVAs revealed that pain, $F(2,24)=18.26, p$ $<.001$, and unpleasantness, $F(2,25)=37.23, p$
$<.001$, subsided within session, with significant reduction both from first to second and from second to third time points. Neither pain nor unpleasantness was significantly affected by stimulation target or type.

\section{Table 2}

Pain and unpleasantness ratings, mean (SD).

\begin{tabular}{llcccccc}
\hline $\begin{array}{l}\text { Stimulation } \\
\text { target }\end{array}$ & $\begin{array}{l}\text { Stimulation } \\
\text { type }\end{array}$ & $\begin{array}{c}0.5 \mathrm{~min} \\
\text { after start }\end{array}$ & $\begin{array}{c}10 \mathrm{~min} \\
\text { after start }\end{array}$ & $\begin{array}{c}19.5 \mathrm{~min} \\
\text { after start }\end{array}$ & $\begin{array}{c}0.5 \mathrm{~min} \\
\text { after start }\end{array}$ & $\begin{array}{c}\text { Unpleasantness } \\
\text { after start }\end{array}$ & $\begin{array}{c}19.5 \mathrm{~min} \\
\text { after start }\end{array}$ \\
\hline \multirow{2}{*}{$\begin{array}{l}\text { Broca's } \\
\text { area }\end{array}$} & Anodal & $2.54(1.57)$ & $1.00(0.00)$ & $1.00(0.00)$ & $2.61(1.42)$ & $1.07(0.27)$ & $1.00(0.00)$ \\
& Cathodal & $2.04(1.15)$ & $1.07(0.27)$ & $1.00(0.00)$ & $2.68(1.88)$ & $1.29(0.83)$ & $1.14(0.36)$ \\
& Sham & $2.93(1.73)$ & $1.14(0.36)$ & $1.00(0.00)$ & $2.93(1.69)$ & $1.21(0.43)$ & $1.07(0.27)$ \\
Angular & Anodal & $2.27(0.99)$ & $1.31(0.48)$ & $1.00(0.00)$ & $2.38(1.06)$ & $1.38(0.51)$ & $1.08(0.28)$ \\
gyrus & Cathodal & $2.35(1.31)$ & $1.23(0.44)$ & $1.00(0.00)$ & $2.65(1.25)$ & $1.31(0.48)$ & $1.08(0.28)$ \\
& Sham & $2.35(1.25)$ & $1.15(0.38)$ & $1.00(0.00)$ & $2.42(1.08)$ & $1.42(0.49)$ & $1.08(0.28)$ \\
\hline
\end{tabular}

Eight out of 27 participants correctly guessed which of the three sessions was sham, with chance being $9 / 27$. One participant reported possible side effects (headache, fatigue and nausea) that started several hours after cathodal stimulation over Broca's area (participant's first session) and lasted several hours, although there was no direct evidence of these symptoms being related to the stimulation.

\section{Task Results}

Naming task. Accuracy of naming was at ceiling (mean $96.4 \%$, SD $4.6 \%$, range $72.5-100.0 \%$ ). The analysis did not capture significant effects of any factors on accuracy. The number of self-corrections was low (mean $1.1 \%$, SD 2.2\%, range $0.0-12.5 \%$ ), with no significant effects of any factors either.

Mean RT was 1103 ms (SD 117 ms, range 921$1312 \mathrm{~ms}$ ). The analysis revealed main effects of Stimulation Site, $F(1,205.42)=23.86, p<.001$, with participants in the Broca's area group having slower reaction times than participants in the angular gyrus group; Linguistic Condition, $F(2,134.57)=85.11, p$ $<.001$, with two-argument verbs having slower reaction times than one-argument verbs, $p<.001$, and those in turn having slower reaction times than nouns, $p<.001$ (see Figure 2); and Stimulation Type, $F(2,137.95)=6.59, p=.002$, with anodal and sham stimulation yielding slower reaction times than cathodal stimulation, $p=.001$ and $p=.008$ respectively (see Figure 3 ). The analysis also revealed the following interactions: a two-way Stimulation Type by Session Number interaction, $F(4,136.87)=2.88, p=.025$, and a three-way Stimulation Site by Stimulation Type by Session Number interaction, $F(6,67.82)=3.58, p=.004$, indicating that the effects of stimulation types were modulated by the order in which they were administered, and that this modulation varied between stimulation sites (see Figure 4a-b); no other interactions were significant. 


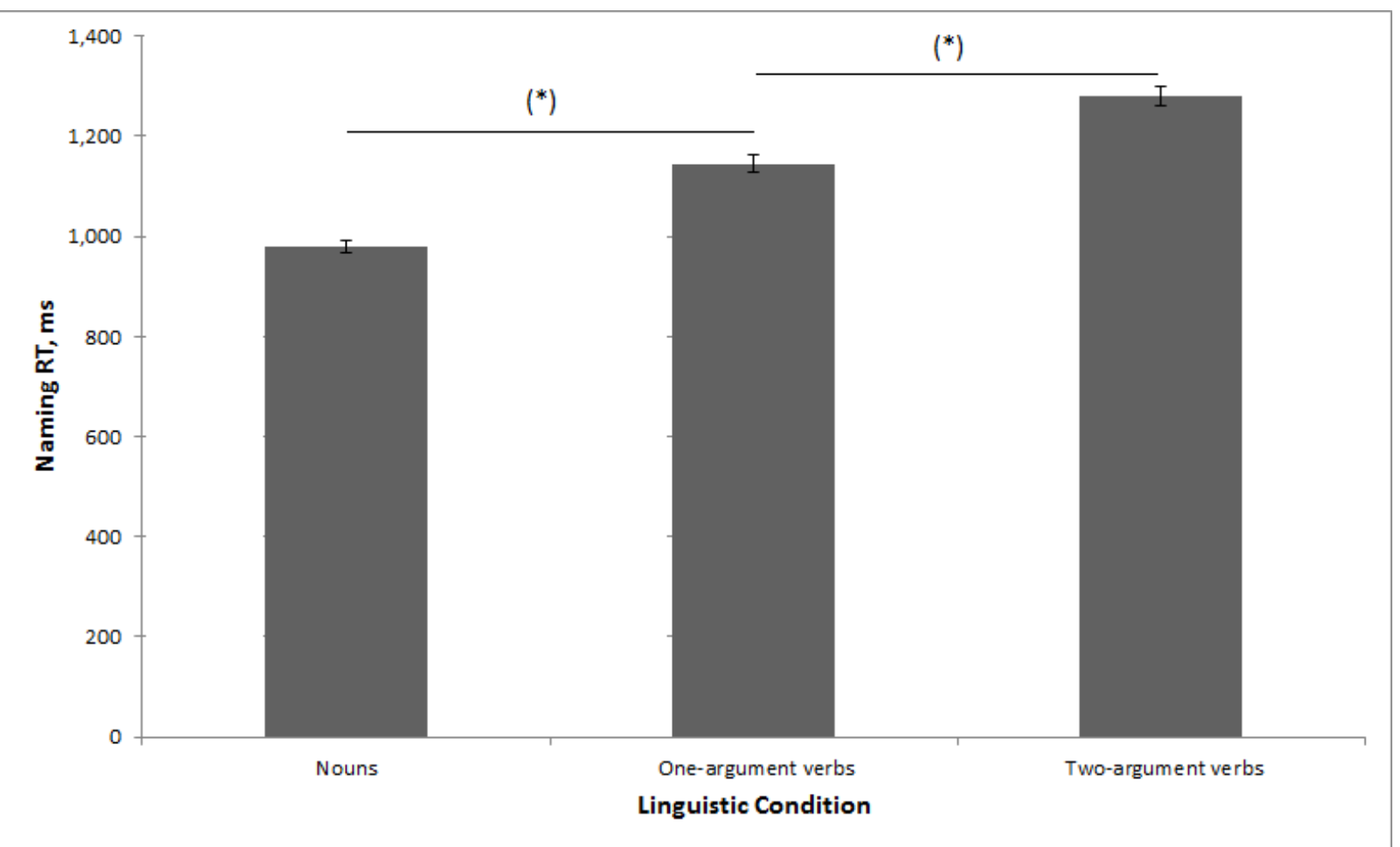

Figure 2. Effect of linguistic condition on naming reaction times. Error bars indicate standard error of the mean. * indicates significant contrasts $(p<.05)$.

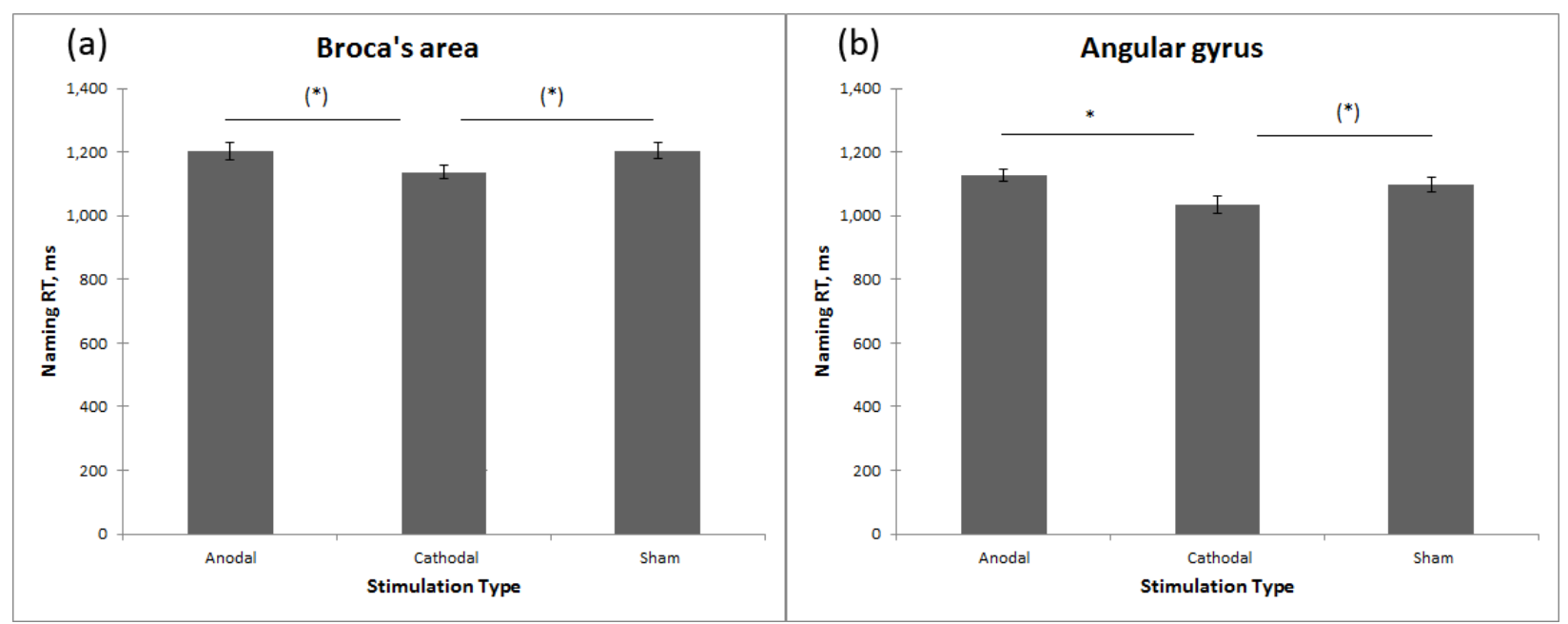

Figure 3. Main effect of stimulation type on naming reaction times. Error bars indicate standard error of the mean. ${ }^{*}$ indicates significant contrasts $(p<.05),\left({ }^{*}\right)$ indicates statistical trends $(.1<p<.05)$ 


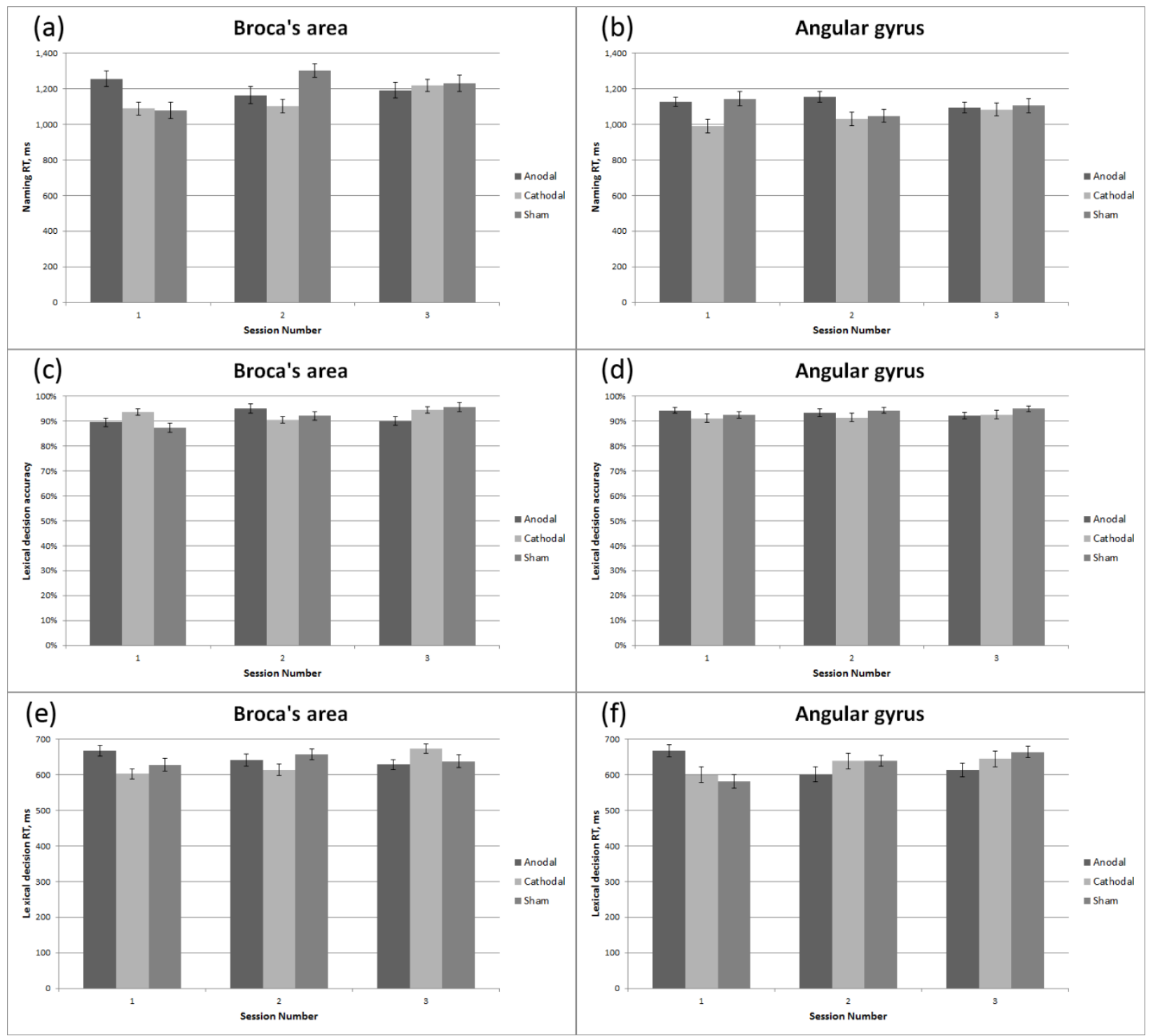

Figure 4. Naming reaction times (a, b), lexical decision reaction accuracy (c, d) and lexical decision reaction times (e, f) across stimulation sessions. Error bars indicate standard error of the mean.

To follow up on the significant three-way Stimulation Site by Stimulation Type by Session Number interaction, we "sliced" the interaction by Stimulation Site and performed separate analyses of naming reaction times in the Broca's area group and the angular gyrus group. In the Broca's area group, we found a main effect of Linguistic Condition, $F(2$, $68.72)=44.88, p<.001$, with two-argument verbs having slower reaction times than one-argument verbs, $p=.019$, and those in turn having slower reaction times than nouns, $p<.001$; a trend for an effect of Session Number, $F(2,67.84)=2.49, p$ $=.088$, with reaction times becoming slower across sessions; a trend for an effect of Stimulation Type, $F(2,71.74)=2.52, p=.087$, with anodal and sham stimulation having slower reaction times than cathodal stimulation, $p=.061$ and $p=.059$ respectively (see Figure 3a); and a two-way Stimulation Type by Session Number interaction, $F(4,71.35)=5.63, p=.001$, indicating that the effects of stimulation type were modulated by the order in which they were administered (see Figure 4a); no other factors or interactions were significant. In the angular gyrus group, we found a main effect of Linguistic Condition, $F(2,52.55)=46.36, p<.001$, with two-argument verbs having slower reaction times than one-argument verbs, $p<.001$, and those in turn having slower reaction times than nouns, $p$ $<.001$; and a main effect of Stimulation Type, $F(2$, $63.34)=4.80, p=.011$, with anodal stimulation and, 
at the level of a statistical trend, sham stimulation having slower reaction times than cathodal stimulation, $p=.003$ and $p=.058$ respectively (see Figure $3 b$ ); no other factors or interactions were significant. For lack of statistical power, we did not follow up any further on the interactions between Stimulation Type and Session Number within the two stimulation sites, but Figure $4 a-b$ provide a visual illustration of these effects, which were not uniform between the two sites.

In order to assess the effects of stimulation without interference from potential carry-over effects, we conducted a complementary analysis, limited to the participants' first sessions and separately for the two stimulation sites. For these data, a Kruskal-Wallis test did not reveal an effect of Stimulation Type on the accuracy or number of self-corrections in nouns or verbs in either the Broca's area or the angular gyrus group. For mean RTs in the Broca's area group (see first group of bars in Figure 1a), a Kruskal-Wallis test revealed trends towards an effect of Stimulation Type for both nouns, $x^{2}(2)=5.23, p$ $=.073$ (driven by anodal stimulation having slower RTs than cathodal stimulation, $p=.026$ ), and verbs, $x^{2}(2)=5.57, p=.062$ (driven by anodal stimulation having slower RTs than sham, $p=.033$ ). For mean RTs in the angular gyrus group (see first group of bars in Figure $1 b$ ), there was a trend towards an effect of Stimulation Type for nouns, $x^{2}(2)=5.09, p$ $=.078$ (driven by cathodal stimulation having faster RTs than anodal stimulation, $p=.026$ ); the speed-up of RTs for cathodal stimulation compared to sham did not reach significance, $p=.134$. There was no effect of Stimulation Type for verbs, $x^{2}(2)=1.53, p$ $=.465$.

Lexical decision task. One participant was excluded from analysis due to non-compliance with the task. After excluding him, the accuracy on the lexical decision task was $93.4 \%$ (SD $4.7 \%$, range $72.8-99.4 \%)$. The analysis revealed a main effect of Linguistic Condition, $F(4,128.23)=2.71, p=.033$, driven by nouns having higher accuracy than oneargument, $p=.040$, two-argument, $p=.090$, and three-argument, $p=.009$, verbs and by non-words having higher accuracy than three argument verbs, $p=.045$; and a two-way Stimulation Type by Session Number interaction, $F(4,144.05)=3.99, p$ $=.004$, indicating that the effects of stimulation type were modulated by the order in which they were administered (see Figure 4c-d); no other factors or interactions were significant.

Mean reaction time was $647 \mathrm{~ms}$ (SD $81 \mathrm{~ms}$, range 491-826 ms). The analysis revealed a two-way
Stimulation Type by Session Number interaction, $F(4,264.85)=6.93, p<.001$, indicating that the effects of stimulation type were modulated by the order in which they were administered (see Figure $4 \mathrm{e}-\mathrm{f})$; no other factors or interactions were significant.

For data from the first session only (see first groups of bars in Figures 4c-f), Kruskal-Wallis tests revealed no effects of Stimulation Type on accuracy or mean RTs in any linguistic condition in either the Broca's area or the angular gyrus group.

\section{Discussion}

The present study is one of the first to apply the novel HD-tDCS method to modulate language processing, and specifically the lexical retrieval of nouns and verbs of varied argument structure complexity. We administered anodal, cathodal, and sham stimulation, targeting Broca's area in one group of neurologically healthy participants and the left angular gyrus in the other group, followed by a naming and a lexical (word/non-word) decision task.

Consistent with the existing psycholinguistic literature, we found that linguistic characteristics of the stimuli affected participants' performance. In the naming task, participants were slower in naming two-argument verbs than one-argument verbs, which in turn were named more slowly than nouns; in the lexical decision task, participants were more accurate for nouns than for verbs, especially the most complex (three-argument) verbs. This adds to the evidence of higher complexity of verb than noun processing (Vigliocco et al., 2011) and of higher complexity of verbs with a greater number of arguments (Kim \& Thompson, 2000; Kiss, 2000; Rodríguez-Ferreiro et al., 2014; Shapiro et al., 1991; Thompson et al., 1997). Importantly, these findings indicate that the experimental task was valid and drew on the processes of lexical retrieval in an expected way. From a psycholinguistic perspective, these results indeed confirm that the complexity effects are generated at the level of lexical retrieval, as that is the process that is shared between the two tasks.

However, contrary to our original hypotheses about the effects of stimulation on particular linguistic conditions, we did not find that the stimulation over the left angular gyrus specifically affected processing of verbs and/or showed a greater effect for verbs with more complex argument structure: the analysis revealed no significant interactions of stimulation type or site with linguistic condition. 
Thus, the present study failed to demonstrate that activation of the left angular gyrus during verb argument structure processing in previous neuroimaging research is due to the area being necessary for verb processing, rather than being merely involved but not crucial for it, which is the limit of what functional neuroimaging research has the potential to show. Lack of verb-specific effects is in line with the results by Marangolo et al. (2013) and Fertonani et al. (2010), who also demonstrated effects of brain stimulation to extend across verbs and nouns. To the best of our knowledge, the rTMS experiment by Cappa et al. (2002) remains the only study that demonstrated any effects specific to verb processing in the context of brain stimulation.

Instead, the primary finding with regard to main effects of stimulation was that cathodal stimulation both over Broca's area and, at the level of a statistical trend in the pairwise comparison to sham, over the left angular gyrus made participants faster on the naming task across both nouns and verbs of varied argument structure complexity; no significant differences were found between anodal stimulation and sham. Quite similarly, in the exploratory analysis of the data subset limited to each participant's first session and thus free from any carry-over effects, anodal stimulation over Broca's area led to slower naming relative to both sham and cathodal stimulation (at the level of a statistical trend). Cathodal stimulation over the left angular gyrus increased the naming speed relative to anodal stimulation (at the level of a statistical trend; an increase in speed relative to sham was similar in size but did not reach significance). This challenges the conclusions of previous tDCS literature with regard to directions of behavioral effects of anodal and cathodal stimulation. With tDCS, anodal stimulation over language-related areas has been traditionally associated with increases in language performance in healthy individuals (Cattaneo et al, 2011; Fertonani et al., 2010; Iyer et al., 2005; Wirth et al., 2011), while cathodal stimulation over language-related areas has been associated with decreased performance (Liuzzi et al., 2010), contrary to our findings. Nonetheless, other effects (e.g., positive effect of cathodal stimulation or lack of effect of anodal stimulation, as in the present study) have been demonstrated before. For example, in a pattern identical to our findings, Filmer et al. (2013) demonstrated improved multitasking performance following cathodal tDCS over the left posterior lateral prefrontal cortex, whereas performance following its anodal stimulation did not differ significantly from sham. Likewise, Pirulli, Fertonani, and Miniussi (2014) demonstrated improved performance in a visual task following cathodal tDCS over the primary visual cortex. Such reports are less numerous but this may partially be due to reporting bias and lack of publishing of null results.

To account for the apparent discrepancy noted above, we point out that facilitatory or detrimental effects of anodal and cathodal stimulation (or lack thereof) may greatly depend on the specific task, stimulation target, electrode montage, current intensity and stimulation duration (Garnett et al., 2015). For example, Batsikadze, Moliadze, Paulus, Kuo, and Nitsche (2013) show that the direction of tDCS effects in the motor domain (excitatory versus inhibitory) may vary depending on current intensity and also suggest that effects of stimulation duration may be nonlinear for intensities greater than $1 \mathrm{~mA}$, as in the present experiment. Pirulli et al. (2014) also show effects of duration and intensity on the behavioral effect of anodal versus cathodal polarity in the visual domain. Thus, it is worth noting that some of the previous reports of enhancing language performance with anodal tDCS or decreasing language performance with cathodal stimulation over language-related areas used either smaller current intensities (1 mA in Liuzzi et al., 2010, and de Vries et al., 2010; $1.5 \mathrm{~mA}$ in Wirth et al., 2011) or other stimulation durations ( 8 or 10 min in Fertonani et al., 2010; 30 min in Wirth et al., 2011) than in the present study. The discrepancy may also be due to specific tasks (word learning in Liuzzi et al., 2010, verbal fluency in Cattaneo et al., 2011, and lyer et al., 2005), stimulation target (left motor cortex in Liuzzi et al., 2010) and electrode montages (such as positioning of the reference electrode), as well as, importantly, to a possible difference in effects of stimulation administered through conventional sponge tDCS and HD-tDCS, the latter having more focal targeting.

Another factor that may have affected the outcome of stimulation is the nature of the task administered during stimulation. Contrary to TMS, tDCS is not considered to induce an action potential, but rather to bring depolarization closer to or further away from the threshold of neural firing. That is, it is considered to "prime" neurons for activation, rather than to induce activation directly. For that reason, it might be expected that task-related involvement of neurons during their stimulation with tDCS may be less relevant than in the case of TMS, where actual neural firing patterns may be reinforced in association with a particular task. This notion, together with the fact that we preferred to keep our outcome-measure tasks "fresh" and thus to avoid ceiling effects or fatigue, led us to use a nonlinguistic 
task during stimulation that was deliberately unrelated to our outcome measures (similarly to, e.g., Cattaneo et al., 2011). Nevertheless, recent advances suggest that tDCS may indeed preferentially modulate neural networks that are active during stimulation (Bikson \& Rahman, 2013; Gill, Shah-Basak, \& Hamilton, 2015). It is possible, therefore, that stimulation effects might be modified if we had used a task that was more closely related to our object of investigation, that is, lexical retrieval and production. In addition, the strength of the behavioral effects of HD-tDCS may have been affected by the time point at which outcome measures were tested, relative to stimulation offset. Recently, Hoy et al. (2013) found that effects of anodal tDCS over the left prefrontal cortex were greater at 40 min post-stimulation compared to 0 min, which was the testing point in the present study. Contrary to that report, however, other evidence suggests that effects may be the strongest immediately post-stimulation (e.g., Fujiyama et al., 2014). So, while the test-timing issue must be considered unresolved at this point, it should be noted that it may have been a factor affecting our behavioral data. These observations again suggest that a larger body of comparable basic research is needed in order to account for apparent inconsistencies in findings (Garnett et al., 2015; Horvath, Forte, \& Carter, 2015).

The effects of anodal and cathodal stimulation on naming reaction times were the same for stimulation over Broca's area and the left angular gyrus. We did find that participants in the Broca's area group were generally slower in naming than participants in the left angular gyrus group across stimulation types. However, since no interactions were observed between the effects of stimulation type and stimulation site, slower naming in the Broca's area group is likely due to individual variability, which occurred by chance even though the two groups had similar ages and education levels, rather than to differential stimulation effects.

Main effects of stimulation were limited to the naming task and were not observed in the lexical decision task, in either the primary analysis of the full data set or the exploratory analysis limited to data from participants' first sessions only. One account for this is that lexical decision may simply be a less "natural" task than naming, yielding higher individual variability and thus providing less power to detect any group effects. However, also given the absence of interactions between stimulation (type or site) and linguistic categories, it is more likely that the difference in outcomes is due to the qualitatively different cognitive and linguistic processes involved in the two tasks. Compared to lexical decision, naming involves the additional components of visual processing, object recognition, conceptual/semantic processing, phonological and articulatory planning, and speech motor execution-modulation of any of which could have contributed to the observed effect of stimulation. Many previous studies into the impact of tDCS on language processing have used naming tasks similar to that used in the present study, so it may be considered a fairly standard outcome measure for language studies (Fertonani et al., 2010; Holland et al., 2011; Sparing et al., 2008; Wirth et al., 2011; etc.). However, while naming is certainly an ecologically valid and functionally relevant task that has a potential both as an outcome measure and as a target for aphasia treatment, investigation of effects of stimulation on more diverse linguistic tasks could shed more light on the nature of observed effects (i.e., which specific linguistic sub-processes are modulated by stimulation of focal brain regions).

Besides the increase in naming speed under conditions of cathodal stimulation over Broca's area and the left angular gyrus, another significant finding of the study was the interaction between session number and stimulation type, indicating that the effect of anodal and cathodal stimulation varied depending on whether these stimulation types were administered in participant's first, second, or third session. We originally introduced the factor of session number into the statistical model in order to account for any main effects of task practice over time. No such main effects of session number were observed, but it did consistently modulate the effect of stimulation across outcome measures and tasks (in naming reaction times, lexical decision accuracy, and lexical decision reaction times). Since our study was not originally designed to investigate any such interactions, it did not have enough power to more specifically explore how stimulation effects differed in the first, second, and third session. More research is warranted that would investigate this question by having large sample sizes in stimulation order groupings. One potential account for the emerging interaction of stimulation type and order may be that stimulation effects are modulated by task novelty, consistent with findings by Dockery, Hueckel-Weng, Birbaumer, and Plewnia (2009) who showed that effects of tDCS in a planning task (the Tower of London) were specific to the training phase. However, in the present study the interaction was found not only in the lexical decision task, which was likely novel to most or all participants in their first session, but also in the more "natural" naming 
task. Thus, a more likely possibility is that the interactions reflect physiological carry-over effects between stimulation types. So far, prolonged effects of tDCS have typically been reported after administration of multiple stimulation sessions (Brunoni et al., 2012; Olma et al., 2013). However, it is possible that multiple sessions are only necessary in order for behavioral effects to last without further stimulation, whereas if a different type of stimulation is administered as a follow-up, its effects may be modified even by a single previous administration of stimulation. These findings have important implications for the field: first, they call for further research on the duration of HD-tDCS effects; but also, they have implications for design of further research that is not focused on long-lasting effects. In this case, between-subjects designs where each participant only receives one stimulation type may possibly be a better choice than within-subject (e.g., cross-over) designs, until more is known about the effects of different stimulation polarities on one another.

Since HD-tDCS is a novel method, an additional aim of the study was to obtain more information on the method itself. The findings add to the evidence of high safety and tolerability of HD-tDCS (Borckardt, 2012; Garnett \& den Ouden, 2015). Participants gave relatively low pain and unpleasantness ratings and these subsided within a 20 -min session at $2 \mathrm{~mA}$. Only one participant possibly experienced short-term side effects. This suggests good tolerability and thus a high potential for routine clinical use of HDtDCS.

\section{Conclusions}

We found that cathodal stimulation over both Broca's area and the left angular gyrus increased naming speed for both verbs and nouns, challenging the traditional view of cathodal stimulation as suppressive or leading to decreased performance. The effect did not extend to the lexical decision task. Additionally, effects of specific stimulation types depended on the order of their administration, suggesting possible physiological carry-over and/or task novelty effects. These results are relevant to the application of HD-tDCS to enhance and direct neural plasticity in patients with neurogenic language disorders.

\section{Acknowledgements}

The authors thank Julius Fridriksson, Paul Fillmore, Marom Bikson, and Abhishek Datta for their help with technology; and Kelly Marlowe, Ece Bayram, and Keiko Bridwell for their help with data analysis. Research was supported by ASPIRE-I grant \#11560-13-32582 (DdO) of the University of South Carolina. The article was partly prepared within the framework of the Basic Research Program at the National Research University Higher School of Economics (HSE) and supported within the framework of a subsidy granted to the HSE by the Government of the Russian Federation for the implementation of the Global Competitiveness Program.

\section{References}

Akinina, Y., Malyutina, S., Ivanova, M., Iskra, E., Mannova, E., \& Dragoy, O. (2015). Russian normative data for 375 action pictures and verbs. Behavior Research Methods, 47(3), 691707. http://dx.doi.org/10.3758/s13428-014-0492-9

Baayen, R. H., \& Milin, P. (2010). Analyzing reaction times. International Journal of Psychological Research, 3(2), 12-28.

Baker, J. M., Rorden, C., \& Fridriksson, J. (2010). Using transcranial direct-current stimulation to treat stroke patients with aphasia. Stroke, 41(6), 1229-1236. $\mathrm{http}: / / \mathrm{dx}$.doi.org/10.1161/STROKEAHA.109.576785

Bartlett, M. S. (1947). The use of transformations. Biometrics, $3(1), 39-52$.

Batsikadze, G., Moliadze, V., Paulus, W., Kuo, M.-F., \& Nitsche, M. A. (2013). Partially non-linear stimulation intensitydependent effects of direct current stimulation on motor cortex excitability in humans. Journal of Physiology, 591(7), 1987-2000. http://dx.doi.org/10.1113/jphysiol.2012.249730

Bazzini, A., Zonca, G., Craca, A., Cafforio, E., Cellamare, F., Guarnaschelli, C., ... Luzzatti, C. (2012). Rehabilitation of argument structure deficits in aphasia. Aphasiology, 26(12), 1440-1460. http://dx.doi.org/10.1080/02687038.2012.690023

Bikson, M., \& Rahman, A. (2013). Origins of specificity during tDCS: Anatomical, activity-selective, and input-bias mechanisms. Frontiers in Human Neuroscience, 7, 688. http://dx.doi.org/10.3389/fnhum.2013.00688

Boersma, P. (2001). Praat, a system for doing phonetics by computer. Glot International, 5(9-10), 341-345.

Borckardt, J. J., Bikson, M., Frohman, H., Reeves, S. T., Datta, A., Bansal, V., ... George, M. S. (2012). A pilot study of the tolerability and effects of high-definition transcranial direct current stimulation (HD-tDCS) on pain perception. Journal of Pain, 13(2), 112-120. http://dx.doi.org/10.1016/j.jpain.2011.07.001

Brunoni, A. R., Nitsche, M. A., Bolognini, N., Bikson, M., Wagner, T., Merabet, L., ... Fregni, F. (2012). Clinical research with transcranial direct current stimulation (tDCS): challenges and future directions. Brain Stimulation, 5(3), 175-195. http://dx.doi.org/10.1016/j.brs.2011.03.002

Cappa, S. F., Sandrini, M., Rossini, P. M., Sosta, K., \& Miniussi, C. (2002). The role of the left frontal lobe in action naming: rTMS evidence. Neurology, 59(5), 720-723. http://dx.doi.org/10.1212/WNL.59.5.720

Cattaneo, Z., Pisoni, A., \& Papagno, C. (2011). Transcranial direct current stimulation over Broca's region improves phonemic and semantic fluency in healthy individuals. Neuroscience, 183, 64-70. http://dx.doi.org/10.1016/j.neuroscience.2011.03.058

Coltheart, M. (1981). The MRC Psycholinguistic Database. Quarterly Journal of Experimental Psychology, 33(4), 497505. http://dx.doi.org/10.1080/14640748108400805

Datta, A., Bansal, V., Diaz, J., Patel, J., Reato, D., \& Bikson, M. (2009). Gyri-precise head model of transcranial direct current stimulation: Improved spatial focality using a ring electrode 
versus conventional rectangular pad. Brain Stimulation, 2(4), 201-207. http://dx.doi.org/10.1016/j.brs.2009.03.005

Davis, N. J., Gold, E., Pascual-Leone, A., \& Bracewell, R. M (2013). Challenges of proper placebo control for non-invasive brain stimulation in clinical and experimental applications. European Journal of Neuroscience, 38(7), 2973-2977. http://dx.doi.org/10.1111/ejn.12307

De Vries, M. H., Barth, A. C. R., Maiworm, S., Knecht, S. Zwitserlood, P., \& Flöel, A. (2010). Electrical stimulation of Broca's area enhances implicit learning of an artificial grammar. Journal of Cognitive Neuroscience, 22(11), 24272436. http://dx.doi.org/10.1162/jocn.2009.21385

Den Ouden, D.-B., Fix, S., Parrish, T. B., \& Thompson, C. K. (2009). Argument structure effects in action verb naming in static and dynamic conditions. Journal of Neurolinguistics, 22(2), http://dx.doi.org/10.1016/j.jneuroling.2008.10.004

Devlin, J. T., \& Watkins, K. E. (2007). Stimulating Language: Insights from TMS. Brain, 130(3), 610-622. http://dx.doi.org/10.1093/brain/awl331

Dockery, C. A., Hueckel-Weng, R., Birbaumer, N., \& Plewnia, C. (2009). Enhancement of planning ability by transcranial direct current stimulation. Journal of Neuroscience, 29(22), 72717277. http://dx.doi.org/10.1523/JNEUROSCI.0065-09.2009

Fertonani, A., Rosini, S., Cotelli, M., Rossini, P. M., \& Miniussi, C. (2010). Naming facilitation induced by transcranial direct current stimulation. Behavioural Brain Research, 208(2), 311318. http://dx.doi.org/10.1016/j.bbr.2009.10.030

Filmer, H. L., Mattingley, J. B., \& Dux, P. E. (2013). Improved multitasking following prefrontal tDCS. Cortex, 49(10), 28452852. http://dx.doi.org/10.1016/j.cortex.2013.08.015

Fiori, V., Coccia, M., Marinelli, C. V., Vecchi, V., Bonifazi, S., Ceravolo, M. G., ... Marangolo, P. (2011). Transcranial direct current stimulation improves word retrieval in healthy and nonfluent aphasic subjects. Journal of Cognitive Neuroscience, 23(9), 2309-2323. http://dx.doi.org/10.1162/jocn.2010.21579

Flöel, A., Meinzer, M., Kirstein, R., Nijhof, S., Deppe, M., Knecht, S., \& Breintenstein, C. (2011). Short-term anomia training and electrical brain stimulation. Stroke, 42(7), 2065-2067. http://dx.doi.org/10.1161/STROKEAHA.110.609032

Fridriksson, J., Richardson, J. D., Baker, J. M., \& Rorden, C. (2011). Transcranial direct current stimulation improves naming reaction time in fluent aphasia: a double-blind, shamcontrolled study. Stroke, 42(3), 819-821. http://dx.doi.org/10.1161/STROKEAHA.110.600288

Fujiyama, H., Hyde, J., Hinder, M. R., Kim, S.-J., McCormack, G. H., Vickers, J. C., \& Summers, J. J. (2014). Delayed plastic responses to anodal tDCS in older adults. Frontiers in Aging Neuroscience 6 ,

115 http://dx.doi.org/10.3389/fnagi.2014.00115

Garnett, E. O., Malyutina, S., Datta, A., \& den Ouden, D.-B. (2015). On the use of the terms anodal and cathodal in highdefinition transcranial direct current stimulation: A technical note. Neuromodulation: Technology at the Neural Interface. Advance online publication http://dx.doi.org/10.1111/ner.12320

Garnett, E. O., \& den Ouden, D.-B. (2015). Validating a sham condition for use in high definition transcranial direct current stimulation. Brain Stimulation, 8(3), 551-554. http://dx.doi.org/10.1016/j.brs.2015.01.399

Gill, J., Shah-Basak, P. P., \& Hamilton, R. (2015). It's the thought that counts: Examining the task-dependent effects of transcranial direct current stimulation on executive function. Brain Stimulation, 8(2), 253-259. http://dx.doi.org/10.1016/j.brs.2014.10.018

Guleyupoglu, B., Febles, N., Minhas, P., Hahn, C., \& Bikson, M. (2014) Reduced discomfort during high-definition transcutaneous stimulation using $6 \%$ benzocaine. Frontiers in
Neuroengineering, 7

28.

http://dx.doi.org/10.3389/fneng.2014.00028

Hagoort, P. (2005). On Broca, brain, and binding: a new framework. Trends in Cognitive Sciences, 9(9), 416-423. http://dx.doi.org/10.1016/j.tics.2005.07.004

Holland, R., \& Crinion, J. (2012). Can tDCS enhance treatment of aphasia after stroke? Aphasiology, 26(9), 1169-1191. http://dx.doi.org/10.1080/02687038.2011.616925

Holland, R., Leff, A. P., Josephs, O., Galea, J. M., Desikan, M., Price, C. J., ... Crinion, J. (2011). Speech facilitation by left inferior frontal cortex stimulation. Current Biology, 21(16), 1403-1407. http://dx.doi.org/10.1016/j.cub.2011.07.021

Horvath, J. C., Forte, J. D., \& Carter, O. (2015). Evidence that transcranial direct current stimulation (tDCS) generates littleto-no reliable neurophysiologic effect beyond MEP amplitude modulation in healthy human subjects: A systematic review, Neuropsychologia 66 213-236 http://dx.doi.org/10.1016/j.neuropsychologia.2014.11.021

Hoy, K. E., Emonson, M. R. L., Arnold, S. L., Thomson, R. H., Daskalakis, Z. J., \& Fitzgerald, P. B. (2013). Testing the limits: Investigating the effect of tDCS dose on working memory enhancement in healthy controls. Neuropsychologia, 51(9), $1777-1784$ http://dx.doi.org/10.1016/j.neuropsychologia.2013.05.018

Hoyle, M. H. (1973). Transformations-An introduction and a bibliography. International Statistical Review, 41(2), 203-223.

lyer, M. B., Mattu, U., Grafman, J., Lomarev, M., Sato, S., Wassermann, E. M. (2005). Safety and cognitive effect of frontal DC brain polarization in healthy individuals. Neurology, 64(5),

872-875 http://dx.doi.org/10.1212/01.WNL.0000152986.07469.E9

Kessler, S. K., Turkeltaub, P. E., Benson, J. G., \& Hamilton, R. H. (2012). Differences in the experience of active and sham transcranial direct current stimulation. Brain Stimulation, 5(2), 155-162. http://dx.doi.org/10.1016/j.brs.2011.02.007

Kim, M., \& Thompson, C. K. (2000). Patterns of comprehension and production of nouns and verbs in agrammatism: Implications for lexical organization. Brain and Language, 74(1), 1-25. http://dx.doi.org/10.1006/brln.2000.2315

Kiss, K. (2000). Effect of verb complexity on agrammatic aphasics' sentence production. In: R. Bastiaanse \& $Y$. Grodzinsky (Eds.). Grammatical disorders in aphasia: $A$ neurolinguistic perspective (pp. 123-151). London: Whurr.

Liuzzi, G., Freundlieb, N., Ridder, V., Hoppe, J., Heise, K., Zimerman, M., ... Hummel, F. C. (2010). The involvement of the left motor cortex in learning of a novel action word lexicon. Current Biology, 20(19), 1745-1751. http://dx.doi.org/10.1016/j.cub.2010.08.034

Marangolo, P., Fiori, V., Di Paola, M., Cipollari, S., Razzano, C., Oliveri, M., \& Caltagirone, C. (2013). Differential involvement of the left frontal and temporal regions in verb naming: $A$ tDCS treatment study. Restorative Neurology and Neuroscience, 31(1), 63-72. http://dx.doi.org/10.3233/RNN120268

Medler, D. A., \& Binder, J. R. (2005). MCWord: An On-Line Orthographic Database of the English Language. http://www.neuro.mcw.edu/mcword/

Minhas, P., Bansal, V., Patel, J., Ho, J. S., Diaz, J., Datta, A., \& Bikson, M. (2010). Electrodes for high-definition transcutaneous DC stimulation for applications in drug delivery and electrotherapy, including tDCS. Journal of Neuroscience Methods, 190(2), 188-197. http://dx.doi.org/10.1016/j.jneumeth.2010.05.007

Monti, A., Ferrucci, R., Fumagalli, M., Mameli, F., Cogiamanian, F., Ardolino, G., \& Priori, A. (2013). Transcranial direct current stimulation (tDCS) and language. Journal of Neurology, Neurosurgery and Psychiatry, 84(8), 832-842. http://dx.doi.org/10.1136/jnnp-2012-302825

Naeser, M. A., Martin, P. I., Ho, M., Treglia, E., Kaplan, E., Bashir, S., \& Pascual-Leone, A. (2012). Transcranial magnetic 
stimulation and aphasia rehabilitation. Archives of Physical Medicine and Rehabilitation, 93(Suppl. 1), S26-S34. http://dx.doi.org/10.1016/j.apmr.2011.04.026

Olma, M. C., Dargie, R. A., Behrens, J. R., Kraft, A., Irlbacher, K., Fahle, M., \& Brandt, S. A. (2013). Long-term effects of serial anodal tDCS on motion perception in subjects with occipital stroke measured in the unaffected visual hemifield. Frontiers in Human Neuroscience, 7, 314. http://dx.doi.org/10.3389/fnhum.2013.00314

Pirulli, C., Fertonani, A., \& Miniussi, C. (2014). Is neural hyperpolarization by cathodal stimulation always detrimental at the behavioral level? Frontiers in Behavioral Neuroscience, 8(226). http://dx.doi.org/10.3389/fnbeh.2014.00226

Price, A., Bonner, M., Hamilton, R., Peelle, J., \& Grossman, M. (2015). Modulating language comprehension using HD-tDCS. Poster presented at the NYC Neuromodulation Conference, New York, January 9-11, 2015.

Price, A. R., McAdams, H., Grossman, M., \& Hamilton, R. H. (2015). A Meta-analysis of Transcranial Direct Current Stimulation Studies Examining the Reliability of Effects on Language Measures. Brain Stimulation. Advance online publication. http://dx.doi.org/ 10.1016/j.brs.2015.06.013

Richardson, J. D., Fillmore, P., Datta, A., Truong, D., Bikson, M., \& Fridriksson, J. (2014). Toward development of sham protocols for high-definition transcranial direct current stimulation (HD-tDCS). NeuroRegulation, 1(1), 62-72. http://dx.doi.org/10.15540/nr.1.1.62

Rodríguez-Ferreiro, J., Andreu, L., \& Sanz-Torrent, M. (2014). Argument structure and the representation of abstract semantics. PLoS ONE, 9(8). http://dx.doi.org/10.1371/journal.pone.0104645

Scholz, A. (2002). Mechanisms of (local) anaesthetics on voltagegated sodium and other ion channels. British Journal of Anaesthesia, 89(1), 52-61. http://dx.doi.org/10.1093/bja/aef163

Shapiro, L. P., Brookins, B., Gordon, B., \& Nagel, N. (1991). Verb effects during sentence processing. Journal of Experimental Psychology: Learning, Memory and Cognition, 17(5), 983996. http://dx.doi.org/10.1037/0278-7393.17.5.983

Sparing, R., Dafotakis, M., Meister, I. G., Thirugnanasambandam, N., \& Fink, G. R. (2008). Enhancing language performance with non-invasive brain stimulation-a transcranial direct current stimulation study in healthy humans. Neuropsychologia, 46(1), 261-268. http://dx.doi.org/10.1016/j.neuropsychologia.2007.07.009

Stagg, C. J. (2014). The physiological basis of brain stimulation In: R. C. Kadosh (Ed.). The stimulated brain: Cognitive enhancement using non-invasive brain stimulation (pp. 145177). London: Elsevier Academic Press.

Stagg, C. J., \& Nitsche, M. A. (2011). Physiological basis of transcranial direct current stimulation. Neuroscientist, 17(1), 37-53. http://dx.doi.org/10.1177/1073858410386614

Thompson, C. K., Bonakdarpour, B., Fix, S. C., Blumenfeld, H. K., Parrish, T. B., Gitelman, D. R., \& Mesulam, M.-M. (2007). Neural correlates of verb argument structure processing. Journal of Cognitive Neuroscience, 19(11), 1753-1767. http://dx.doi.org/10.1162/jocn.2007.19.11.1753

Thompson, C. K., Bonakdarpour, B., \& Fix, S. F. (2010). Neural mechanisms of verb argument structure processing in agrammatic aphasic and healthy age-matched listeners. Journal of Cognitive Neuroscience, 22(9), 1993-2011. http://dx.doi.org/10.1162/jocn.2009.21334

Thompson, C. K., Lange, K. L., Schneider, S. L., \& Shapiro, L. P. (1997). Agrammatic and non-brain-damaged subjects' verb and verb argument structure production. Aphasiology, 11(45), 473-490.

Thompson, C. K., Riley, E. A., den Ouden, D.-B., MeltzerAsscher, A., \& Lukic, S. (2013). Training verb argument structure production in agrammatic aphasia: Behavioral and neural recovery patterns. Cortex, 49(9), 2358-2376. http://dx.doi.org/10.1016/j.cortex.2013.02.003

Thompson-Schill, S. L. (2005). Dissecting the language organ: A new look at the role of Broca's area in language processing. In: A. Cutler (Ed.), Twenty-first century psycholinguistics: Four cornerstones (pp. 173-189). Hillsdale NJ: Lawrence Erlbaum Associates.

Vigliocco, G., Vinson, D. P., Druks, J., Barber, H., \& Cappa, S. F. (2011). Nouns and verbs in the brain: A review of behavioural, electrophysiological, neuropsychological and imaging studies. Neuroscience \& Biobehavioral Reviews, 35(3), http://dx.doi.org/10.1016/j.neubiorev.2010.04.007

Vigneau, M., Beaucousin, V., Hervé, P. Y., Duffau, H., Crivello, F., Houdé, O., ... Tzourio-Mazoyer, N. (2006). Meta-analyzing left hemisphere language areas: phonology, semantics, and sentence processing. Neurolmage, 30(4), 1414-1432. http://dx.doi.org/10.1016/j.neuroimage.2005.11.002

Vines, B. W., Norton, A. C., \& Schlaug, G. (2011). Non-invasive brain stimulation enhances the effects of melodic intonation therapy. Frontiers in Psychology, 2, 230. http://dx.doi.org/10.3389/fpsyg.2011.00230

Wirth, M., Rahman, R. A., Kuenecke, J., Koenig, T., Horn, H., Sommer, W., \& Dierks, T. (2011). Effects of transcranial direct current stimulation (tDCS) on behaviour and electrophysiology of language production. Neuropsychologia, 49(14), 3989-3998. http://dx.doi.org/10.1016/j.neuropsychologia.2011.10.015

You, D. S., Kim, D.-Y., Chun, M. H., Jung, S. E., \& Park, S. J. (2011). Cathodal transcranial direct current stimulation of the right Wernicke's area improves comprehension in subacute stroke patients. Brain and Language, 119(1), 1-5. http://dx.doi.org/10.1016/j.bandl.2011.05.002

Received: July 31, 2015

Accepted: September 18, 2015

Published: October 8, 2015 